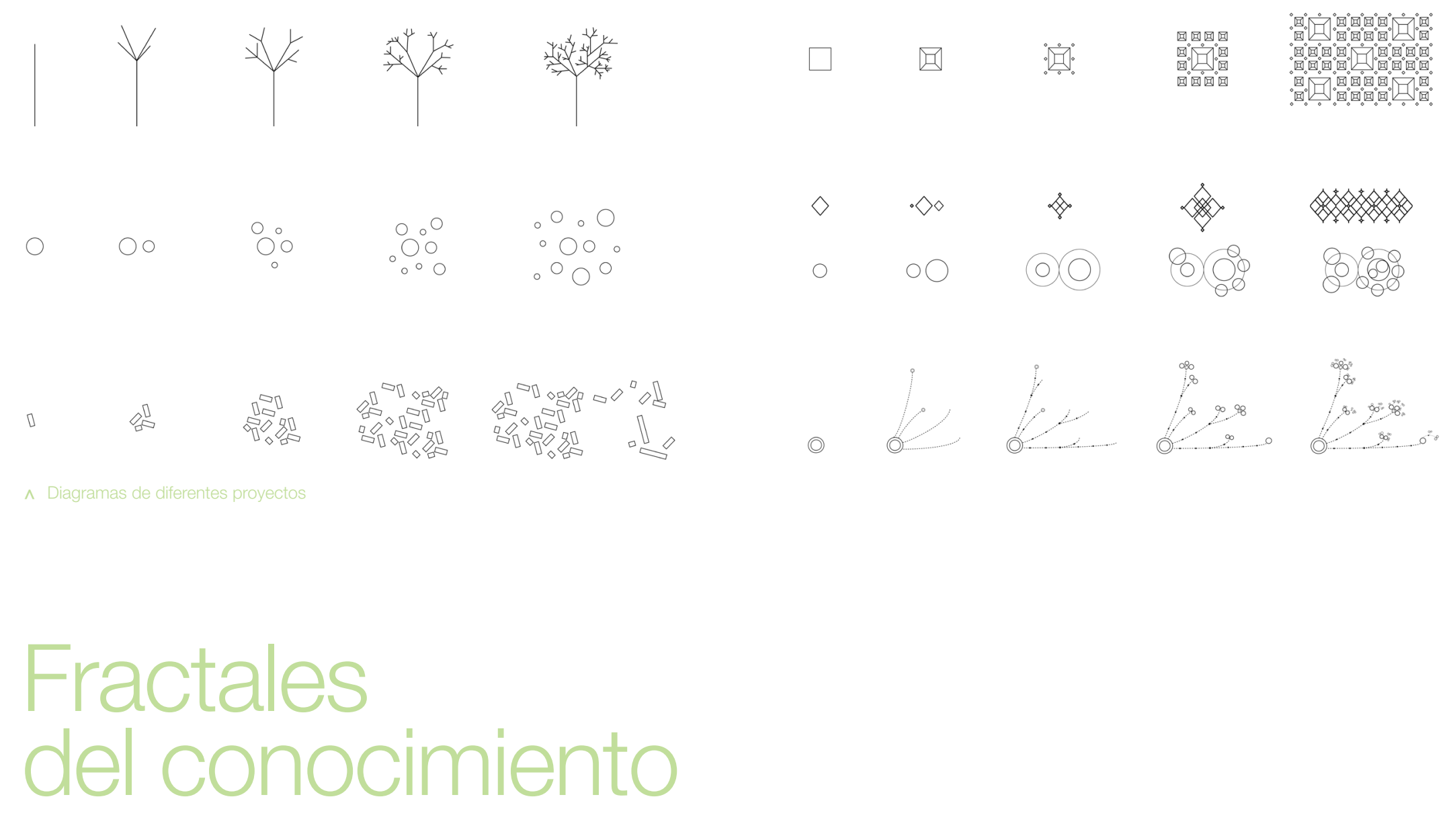

\title{
Xavier Vilalta
}

Recibido 2019.09.27 ::: Aceptado 2019.09.30

DOI: 10.5821/palimpsesto.20.8767

Persona de contacto: xavier@vilalta-architects.com

ORCID: https://orcid. org/0000-0002-9826-8958

Arquitecto por la ETSAB

\begin{abstract}
na de las lecciones más importantes de la Cátedra Blanca con Carlos Ferrater y Alberto Peñín, fue cómo encontrar estrategias para sincronizar con el paisaje mediante la geometría.
\end{abstract}

Esta forma de entender la arquitectura fue madurando con el tiempo y con los proyectos, desde una pequeña guardería en els Alamús, Lleida, hasta un hotel en la Mata Atlántica de Brasil pasando por un mercado en altura en Addis Abeba, Etiopia.

Los proyectos realizados son muy diferentes en cuanto a escala, ubicación y programa, pero mantienen un denominador común en su proceso: hacer el análisis del lugar, desde múltiples perspectivas, parte esencial de la arquitectura y el urbanismo. El resultado es fruto de esta investigación que incorpora mediante la geometría y la materialidad los recursos existentes, la cultura local y las tradiciones.

Durante el primer proyecto en África, el Melaku Center, la investigación sobre la arquitectura vernacular del continente abre un nuevo episodio: el uso de la geometría fractal. La influencia de las investigaciones del etnomatemático Ron Eglash bajo el título "African
Fractals" (1) llevan a pensar los proyectos desde una perspectiva cientifica que tiene su origen en el conocimiento popular. Esas geometrías formuladas por Benoit Mandelbrot se encuentran en todas partes en el continente: desde la artesanía hasta el planeamiento de poblados.

A partir de este descubrimiento, en cada proyecto los fractales serán un elemento ca-racterístico que puede ser la piel del edificio, su volumen o la organización de planeamiento. Se convierten en una estrategia y parte esencial del proceso su origen en la forma poliédrica de relacionarse con el lugar que tiene su origen en la Cátedra Blanca y en la obra de Carlos Ferrater (2).

Al abordar otros territorios después de estas experiencias en Africa (América del Sur o Oriente Medio), el conocimiento ancestral será una materia prima de donde sorprendentemente existen también propiedades de autosimilaridad, independencia de escala,

complejidad y perímetro infinito. El uso de los fractales no se encuentra solo en África si no que aparece en los planeamientos de poblados en Brasil o en las los detalles de la arquitectura vernacular de Qatar.
Aún en este proceso, que como un fractal sigue abierto, se plantea en cada proyecto encontrar formas de hacer Arquitectura que puedan mejorar la relación entre la comunidades y su entorno. La geometría fractal tiene su origen en el conocimiento ancestral de los territorios donde se proyecta y nos sirve para incorporar de una forma contemporánea la tradición, la cultura local y los recursos existentes, buscando a través de la Arquitectura una mejor relación entre nosotros y la naturaleza.

BIBLIOGRAFÍA

(1) African Fractals: Modern Computing and Indigenous Design. Ron Eglash. Rutgers University Press. ISBN-10: 0813526140.
ISBN-13: 978-0813526140.

(2) Sincronizar la geometría: Paisaje, arquitectura construcción. Carlos Ferrater. Actar. ISBN-10: 8496540359.

XAVIER VILALTA es Arquitecto. Ha sido Profesor de Departamento de Proyectos Arquitectónicos de la ETSAB, Universidad Politécnica de Catalunya (UPC).
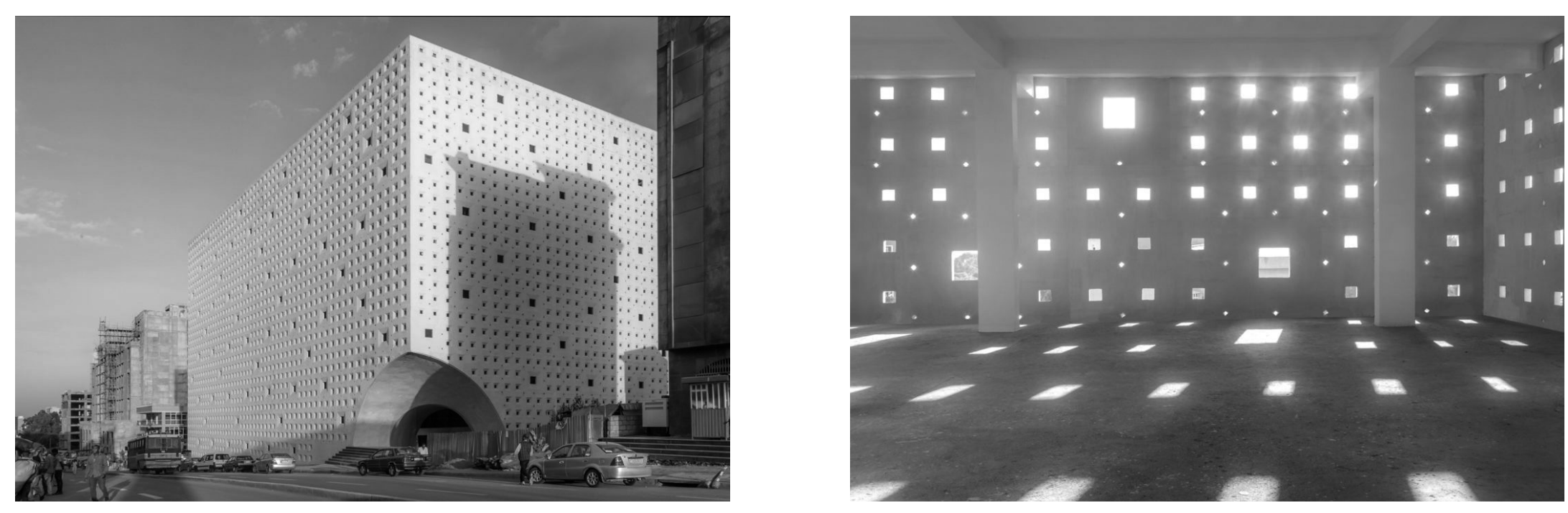